\section{Development of a bird habitat resource classification scheme based on vegetation structure analysis}

\author{
Peter S. Lee ${ }^{1, *}$ and Brendan G. Mackey ${ }^{2}$ \\ ${ }^{1}$ Hanyang University, 622-ho 204-dong, \\ Wangsimni-ro 222, Seongdong-gu, Seoul 04763, Republic of Korea \\ ${ }^{2}$ Griffith School of Environment, Gold Coast Campus, \\ Griffith University, QLD 4222, Australia
}

In order to design a conservation strategy for birds inhabiting the Great Western Woodlands (GWW) in southwestern Australia, we adopted a new approach for classifying birds into functional groups (BHFGs) based on an analysis of vegetation structure-related habitat resources (VHR). On the basis of hierarchical cluster analysis of the VHR variables we selected here, we selected a model that incorporated nine-BHFGs. This yielded a classification system that, due to our different input sources, is distinct from an existing foraging guild-based system. In conjunction with GIS technique, this new classification system has potential for effectively predicting and mapping landscape-scale habitat distribution.

Keywords: Bird habitat, functional group classification, landscape-scale analysis, sustainable management, vegetation structure analysis.

IN order to develop a sustainable conservation strategy for bird species, it is necessary to effectively identify and anticipate the distribution of bird habitats. Grouping schemes based on the community scale, such as guilds, have primarily focused on traits related to bird feeding behaviours and/or sources, whereas in many studies certain vegetation structural attributes, including vegetation height and density and crown size have been proven to be strongly related to bird habitat resources and assemblages $^{1-3}$.

Current bird guidebooks and/or handbooks, and published papers normally deal with ecological, physiological and morphological information from a bird-centric viewpoint. For example, the fact that Brown Honeyeaters typically build their nests $1.3 \mathrm{~m}$ above the ground ${ }^{4}$ is not a factor used for establishing a functional group, but is instead treated as ancillary information. In another study comparing two timber-cutting treatments conducted in oak-hickory forests in the United States, Rodewald and Smith $^{5}$ identified relationships between functional groups of bird species and vegetation structure, with canopynesting functional groups showing a strong relationship with understorey and full-treatment plots, and understorey-nesting functional groups found to be highly correlated with controlled plots in mature forest. These

\footnotetext{
*For correspondence. (e-mail: peter337@hanyang.ac.kr)
}

studies, however, have not addressed the intimate role of vegetation as a fundamental habitat requirement for birds in developing grouping schemes. Using the traditional approach, it is relatively straightforward to anticipate where target bird species can be observed in previously studied areas; however, in unfamiliar regions, habitat prediction is less easily achieved. In this sense, none of the existing grouping schemes seem appropriate for dealing with vegetation structure attributes.

In order to develop a generalized model of bird habitat distribution based on a classification of vegetation structure-related habitat resources rather than simply mapping the habitats of target species, the relationships between vegetation structure and bird assemblages should be comprehensively examined to complement the existing information that guidebooks do provide. As there is no classification scheme at present that focusses on vegetation structure-based habitat resources, it is necessary to develop a new grouping system based on different classifiers. Certain features of bird habitat resources can be translated to vegetation structure due to their strong correlations; for example, foliage height diversity ${ }^{1,2,6}$, tree height $^{3,7,8}$, vegetation biomass ${ }^{2,9,10}$ and understorey plant density ${ }^{11-13}$. Accordingly, in order to devise a new avian grouping system, we decided to use information on bird species that are known to occur within and around our study area, viz. the Great Western Woodlands (GWW) in southwestern Australia. To develop a sustainable conservation plan for bird species inhabiting the GWW, it is necessary to understand the overall structure and composition of the vegetation of this area from the viewpoint of bird habitats. The objectives of this study were thus to: (i) identify explicit vegetation structure-related variables associated with habitat resources, and (ii) devise a classification scheme for GWW birds using the identified structural variables.

The study area is an extant temperate woodland complex in southwestern Australia, located between the Wheat belt to the west and the Nullarbor Plain to the east $^{14}$. The GWW, which comprises a continuous and extensive area of mostly intact native vegetation covering approximately 16 million ha and encompasses a range of vegetation types from shrublands to woodlands ${ }^{15,16}$, is one of the world's largest remnant temperate woodlands, characterized by low annual precipitation $\left(340 \mathrm{~mm} \cdot \mathrm{year}^{-1}\right)$, low nutrient status ${ }^{17}$, and a high biodiversity of native species $^{14,18-23}$. The temperate woodlands are the main vegetation type, covering up to $56 \%$ of the area, with the remainder comprising shrublands $(\sim 20 \%)$, mallee shrublands $(\sim 17 \%)$ and grasslands $(\sim 2 \%)$. Although the GWW lies within a semi-arid zone, in which a history of low precipitation and prolonged weathering has led to the development of infertile soil conditions ${ }^{24}$, it provides critical habitats for both native animals and plants, particularly for 215 bird species ${ }^{14}$. As such, it is considered a valuable natural resource with regard to maintaining a 


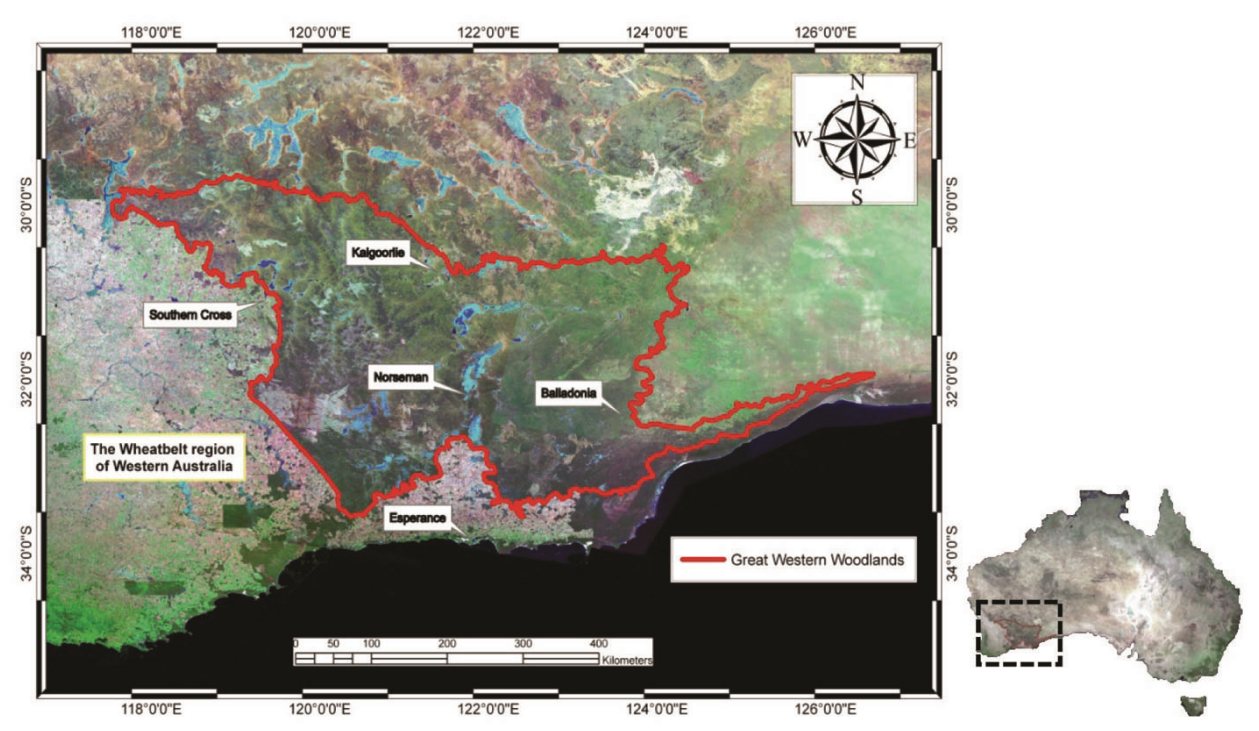

Figure 1. Location of the Great Western Woodlands in Australia.

variety of species under harsh and inhospitable but extensive natural conditions. Figure 1 shows the geographical location of the GWW.

Habitat selection and resources are directly or indirectly related to the structural characters of vegetation ${ }^{1}$. The primary requirements for vegetation structure can be recognized by observing how major groups of bird species share common foraging substrates in a given area. Dominant food sources of target bird species, one of the most important bird habitat resources, can serve as a source of information that indicates unique features in relation to the physical structure of vegetation. Accordingly, in the present study, we have inferred the relationships between habitat resources and vegetation structure variables by examining correlations between bird communities and structural features of vegetation. Subsequently we have selected several critical variables for developing a bird habitat classification scheme.

Owing to insufficient existing research on bird species known to occur within the GWW, information on the same bird species inhabiting other woodlands and forests was examined on a global scale. Identification of the vegetation structure-related habitat resources associated with these bird species was accomplished by reviewing a specialist book (Handbook of Australian, New Zealand \& Antarctic Birds $(H A N Z A B))^{4}$ and published journal papers $^{25}$, focusing on the following three main categories: vegetation height as a vertical factor, and canopy cover and vegetation type as horizontal factors. Two conditions were applied for selecting the vegetation structure-related variables: (i) there should be strong interrelationships between bird habitat resources and vegetation structure, and (ii) the variables should be amenable to vegetation structure measurements commonly used in field surveys. We have used the term 'vegetation habitat resource'
(VHR) to indicate the variables selected in the present study $^{25}$.

To develop a new habitat functional group-based classification system, GWW bird species were assigned to a range of groups by integrating a suite of binary values for each VHR variable. On the basis of a numerical classification approach, GWW bird species were statistically analysed and classified into a set of groups, which are referred to here as bird habitat functional groups (BHFGs). A resulting data matrix for the birds was developed by denoting the VHR values of each bird species. Some species were excluded because of partially missing data for any of the VHR variables.

The hierarchical cluster analysis function in the SPSS 16.0 statistical software package (SPSS Inc., Illinois, USA) was used for examining dissimilarity among the GWW bird species. Dissimilarity was measured using the squared Euclidean distance

$$
D=\sum_{i=1}^{n} \sqrt{\left(\sqrt{\left.x_{i}-y_{i}\right)^{2}}\right.} ; \text { distance coefficient }
$$

with the clustering method of between-groups linkage. The first significant output was a coefficient table of dissimilarity based on the distance measurements (D) between values for combinations of the VHR variables for selected pairs of GWW bird species. As the value of the coefficient decreases, the similarity between two species becomes higher. The second output was a dendrogram depicting statistical distances between paired species according to $D$ values. Pairs of species indicating the shortest distances were repeatedly attracting other closest species one by one, until we obtained clusters of a certain size comprising bird species that exploit similar 
RESEARCH COMMUNICATIONS

Table 1. Examples of Great Western Woodland (GWW) bird species analysed in terms of eight vegetation habitat resource (VHR) variables with detailed original and simplified binary classes

\begin{tabular}{|c|c|c|c|c|c|c|}
\hline $\begin{array}{l}\text { VHR } \\
\text { variables }\end{array}$ & Class & $\begin{array}{l}\text { Binary } \\
\text { class }\end{array}$ & $\begin{array}{l}\text { Australian Ringneck } \\
\text { (Barnardius zonarius) }\end{array}$ & $\begin{array}{l}\text { Brown-headed Honeyeater } \\
\text { (Melithreptus brevirostris) }\end{array}$ & $\begin{array}{c}\text { Crested Shrike-tit } \\
\text { (Falcunculus frontatus) }\end{array}$ & $\begin{array}{l}\text { Dusky Woodswallow } \\
\text { (Artamus cyanopterus) }\end{array}$ \\
\hline $\begin{array}{l}\text { Nest height } \\
\text { (m) }\end{array}$ & $\begin{array}{l}0 \\
0-1 \\
1-2 \\
2-4 \\
4-8 \\
8-12 \\
12-16 \\
16-20 \\
20+\end{array}$ & 2 & - & - & $\bullet$ & $\bullet$ \\
\hline Nest site & $\begin{array}{l}\text { Tree cavity } \\
\text { Tree } \\
\text { Understorey } \\
\text { Low shrub } \\
\text { Grass } \\
\text { Bare-ground } \\
\text { Others } \\
\text { Tree }\end{array}$ & 1 & $\bullet$ & $\bullet$ & - & 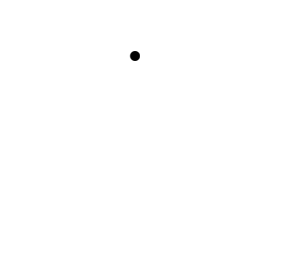 \\
\hline $\begin{array}{l}\text { Forage height } \\
\text { (m) }\end{array}$ & $\begin{array}{l}0 \\
0-1 \\
1-2 \\
2-4 \\
4-8 \\
8-12 \\
12-16 \\
16-20 \\
20-24 \\
24+\end{array}$ & 2 & $\bullet$ & $\bullet$ & $\bullet$ & $\bullet$ \\
\hline Forage site & $\begin{array}{l}\text { Air } \\
\text { Canopy } \\
\text { Perch } \\
\text { Bark } \\
\text { Bare-ground } \\
\text { Water }\end{array}$ & & - & - & - & • \\
\hline Attack method & $\begin{array}{l}\text { Glean } \\
\text { Probe } \\
\text { Scratch } \\
\text { Sally } \\
\text { Attack in the water } \\
\text { Glean + probe } \\
\text { Glean + scratch } \\
\text { Glean + sally } \\
\text { Probe + scratch } \\
\text { Glean + probe + sally }\end{array}$ & & $\bullet$ & $\bullet$ & $\bullet$ & $\bullet$ \\
\hline $\begin{array}{l}\text { Vegetation } \\
\text { type }\end{array}$ & $\begin{array}{l}\text { Forest } \\
\text { Open forest } \\
\text { Woodland } \\
\text { Open woodland } \\
\text { Shrubland } \\
\text { Grassland } \\
\text { Wetland }\end{array}$ & 1 & - & $\bullet$ & $\bullet$ & - \\
\hline $\begin{array}{l}\text { Understorey } \\
\text { density }\end{array}$ & $\begin{array}{l}\text { Dense } \\
\text { Sparse }\end{array}$ & $\begin{array}{l}1 \\
2\end{array}$ & $\bullet$ & $\bullet$ & $\bullet$ & $\bullet$ \\
\hline Food source & $\begin{array}{l}\text { Insectivorous } \\
\text { Carnivorous } \\
\text { Omnivorous } \\
\text { Herbivorous } \\
\text { Aquatic sources } \\
\text { Insectivorous + } \\
\quad \text { carnivorous } \\
\text { Insectivorous + } \\
\quad \text { herbivorous }\end{array}$ & & - & - & - & $\bullet$ \\
\hline
\end{tabular}


Table 2. Distribution of size of membership of GWW bird species for each bird habitat functional group (BHFG) according to the number of BHFGs ranging from 5 to 12 in a series of BHFG classification (BHFGC) models. A BHFGC model comprising nine BHFGs is the most suitable due to good dispersion of BHFGs in it and the size of membership within the BHFGs. Shading highlights BHFGs that have too many or too few member species. A total of 104 bird species were used in the present study for modelling purposes

\begin{tabular}{|c|c|c|c|c|c|c|c|c|}
\hline \multirow[b]{2}{*}{ BHFG } & \multicolumn{8}{|c|}{ BHFG classification model } \\
\hline & 5 groups & 6 groups & 7 groups & 8 groups & 9 groups & 10 groups & 11 groups & 12 groups \\
\hline BHFG1 & 40 & 13 & 13 & 13 & 13 & 13 & 13 & 13 \\
\hline BHFG 2 & 24 & 24 & 24 & 20 & 20 & 20 & 20 & 20 \\
\hline BHFG 3 & 16 & 16 & 16 & 16 & 10 & 10 & 10 & 10 \\
\hline BHFG 4 & 21 & 27 & 27 & 27 & 27 & 27 & 19 & 19 \\
\hline BHFG 5 & 3 & 21 & 14 & 14 & 6 & 6 & 6 & 6 \\
\hline BHFG 6 & & 3 & 7 & 7 & 14 & 14 & 14 & 13 \\
\hline BHFG 7 & & & 3 & 4 & 7 & 5 & 8 & 8 \\
\hline BHFG 8 & & & & 3 & 4 & 4 & 5 & 5 \\
\hline BHFG 9 & & & & & 3 & 3 & 4 & 4 \\
\hline BHFG 10 & & & & & & 2 & 3 & 3 \\
\hline BHFG 11 & & & & & & & 2 & 2 \\
\hline BHFG 12 & & & & & & & & 1 \\
\hline
\end{tabular}

habitat resources. We refer to this process as bird habitat functional group classification (BHFGC).

Through reviewing the published literature, eight VHR variables were selected, including nest height, foraging site and attack method (Table 1$)^{25}$.

The $H A N Z A B^{4}$ was reviewed to enable us to convert the habitat preference of GWW bird species into numeric values for the selected VHR variables. The data collected for the variables were also used to infer the height of vegetation and potential vegetation types, such as woodland and shrubland, for target species. Accordingly, we used the VHR variables as principal classifiers for classifying the GWW bird species. Table 1 provides the VHR values for individual GWW bird species.

For BHFGC, we established a suite of procedures for assigning GWW bird species to the eight VHR variablebased functional groups. As shown in Table 1, each VHR variable comprises several different classes. Owing to insufficient available information on some bird species, it was necessary to create a simple classification scheme using a minimal number of classes, sometimes in binary form. There were some VHR variables for which the classes were based on nominal rather than ordinal or continuous data, and therefore these were not readily reducible; for example, foraging site, attack method and food source. Furthermore, for the categories of nest height and foraging height, it was necessary to include a 'neutral' class to represent bird species with no preference for these variables.

The numerical values for the eight VHR variables and their classes for each of the 104 bird species used as input into the BHFGC were organized in the format presented in Table 1. The results obtained from the BHFGC show the inter-species dissimilarity in terms of vegetation structure-related habitat resources ${ }^{25}$. When the bird spe- cies were clustered from this BHFGC, the resulting groups, or BHFGs, were made up of bird species that are likely to use similar habitat resources in terms of vegetation structure.

In the hierarchical cluster analysis, decision on the optimal number of BHFGs was made based on having sufficient differentiation, while simultaneously ensuring that there was a reasonable spread of bird species between the BHFGs. For a model having only five BHFGs, one group included 40 species (38\% of species selected), whereas another group comprised just three species. In contrast, the models with 10-12 BHFGs had one or two groups that comprised only 1 or 2 species (Table 2).

The BHFGC models encompassing 6-9 BHFGs did not show any significant differences with regard to the number of species per BHFG. In general, a larger number of member BHFGs is likely to provide greater discrimination and more information. If the number of BHFGs is too small, the model may fail to distinguish the principal features of the groups. Taking all the foregoing factors into consideration, the nine-BHFG model constructed in this study was considered to be the most suitable BHFGC model for grouping GWW bird species (Figure 2). Table 3 shows the characteristics of each group in the nine-BHFGC model.

Although there was some overlap between BHFGs at the class level, combinations of the BHFG responses to the eight VHR variables are noticeably different. Consequently, each BHFG was deemed to show distinctive characteristics. Here, BHFG 1 is taken as an example to explain the main characteristics of the nine-BHFGC model, and to delineate the significant differences from the traditional functional group or guild concept. Species in BHFG 1 mainly show a preference for building their 

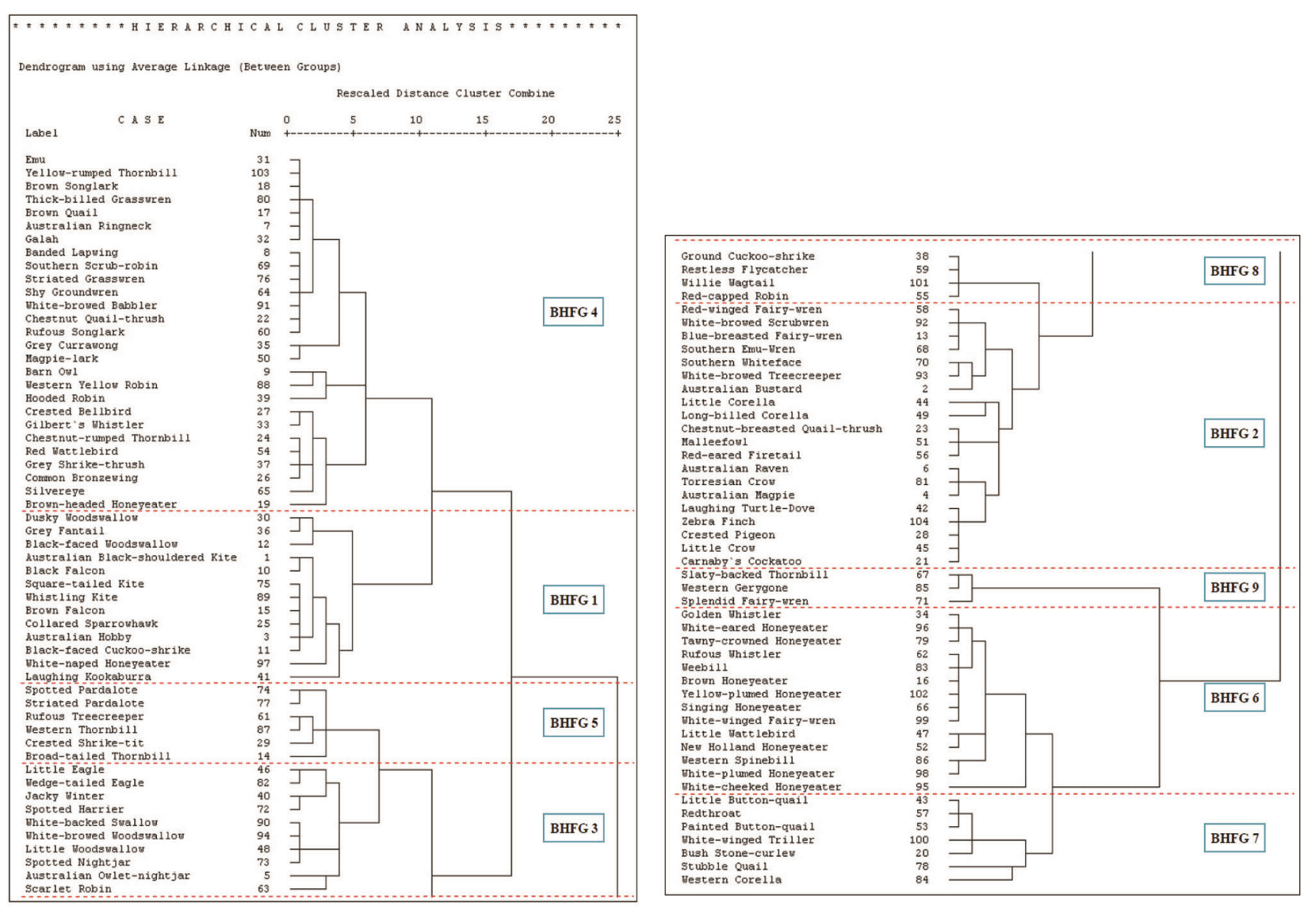

Figure 2. Dendrogram depicting numerical values of distance coefficients ${ }^{25}$ and distinguished into nine groups as bird habitat functional group $(\mathrm{BHFGs})^{25}$. Red dashed lines delimit the BHFGs.

nests on the branches of trees taller than $8 \mathrm{~m}$, foraging on the wing, and inhabiting woodlands and/or open forests (Table 3). This BHFG includes the following two types of bird species based on their food sources, and these are well distinguished in the dendrogram present by Lee et $a l .^{25}$ as follows: raptorial species, including the Australian Black-shouldered Kite, Brown Flacon and Square-tailed Kite, and non-raptorial species such as the Black-faced Cuckoo-shrike, Laughing Kookaburra and White-naped Honeyeater. Although this BHFGC is based on differences in vegetation structure-based habitat resources, it is interesting to note that these member species most probably have predator-prey relationships with species occurring within the same group. Nevertheless, this does not necessarily mean that these species occur sympatrically.

All the habitat resource information relating to the GWW bird species examined in this study was collated from a single source, the $H A N Z A B^{4}$, which covers most Australian bird species. This guidebook provides descriptive expressions and encompasses a significant amount of research performed by many different authors. The exclusive use of this literature resource was intended to avoid potential conflict resulting from the use of different stan- dards among various sources. Although filtering standardized quantitative data on habitat resources for the GWW birds was a difficult process, it was possible to gain a vegetation structure-centric 'active' interpretation of bird assemblages from a bird species-centric 'passive' understanding of their habitat distribution.

Among the eight VHR variables we examined (Table 1), only two, viz. 'attack method' and 'food source', have previously been commonly used in functional group schemes ${ }^{26-31}$. The other six variables were utilized for the first time in developing the new BHFGC scheme used in the present study. However, as none of the VHR variables are newly conceived features and all have been referred to in the existing bird guidebooks at least partially, certain additional procedures, such as recording habitat resources in terms of vegetation structure in more detail, enabled us to perform more powerful analyses of bird habitats using this analytical approach.

In addition, attack method and food source are not directly related to vegetation structure per se. However, as they are the most common features of bird assemblage studies $^{2,13,27,32,33}$, they are useful as ancillary devices in further distinguishing functional groups that are 
Table 3. Details of the nine BHFG classification models. The BHFGs were identified based on a distinct combination of VHR variables and associated (VHR) classes with simplified binary values. All the classes associated with each VHR variable by BHFG are indicated as follows: ' $\bullet$ for multiple bird species assigned to the class, or ' $O$ ' for a single species

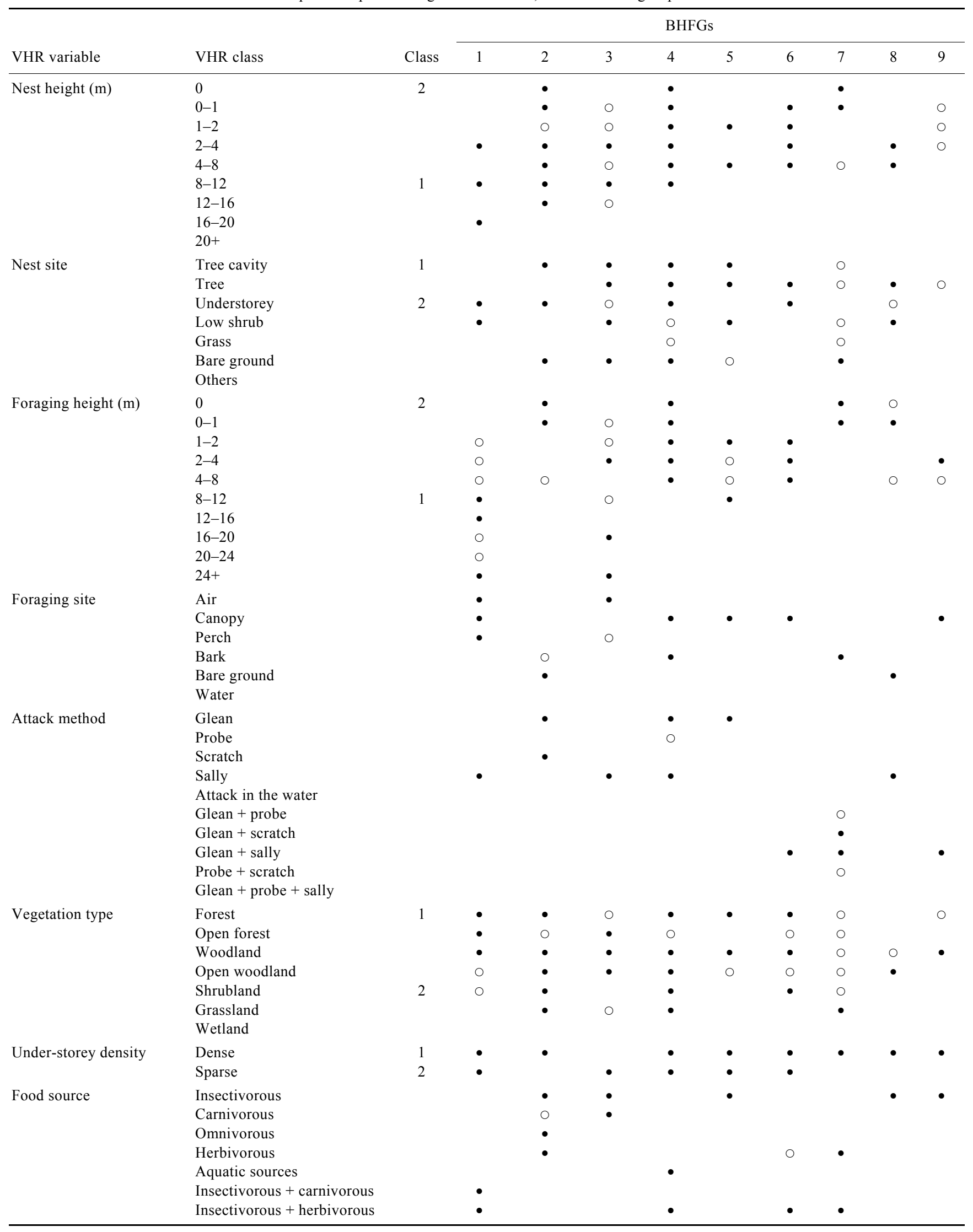


Table 4. Comparison of BHFG classification with MacNally's foraging guild concept for selected GWW bird species examined in the present study

\begin{tabular}{|c|c|c|c|c|c|}
\hline \multirow[b]{2}{*}{$\mathrm{BHFG}^{\mathrm{b}}$} & \multicolumn{3}{|c|}{ BHFGC components } & \multirow[b]{2}{*}{ Bird species } & \multirow[b]{2}{*}{ Foraging guild ${ }^{\mathrm{a}}$} \\
\hline & Attack method ${ }^{\mathrm{c}}$ & Foraging height $^{\mathrm{d}}$ & Foraging site ${ }^{\mathrm{e}}$ & & \\
\hline 1 & 4 & 3 & 1 & Dusky Woodswallow & 2 \\
\hline 1 & 4 & 4 & 1 & Grey Fantail & 2 \\
\hline 1 & 4 & 5 & 3 & Laughing Kookaburra & 3 \\
\hline 1 & 4 & 6 & 2 & Black-faced Cuckoo-shrike & 7 \\
\hline 1 & 6 & 6 & 2 & White-naped Honeyeater & 8 \\
\hline 2 & 1 & 2 & 5 & Australian Magpie & 4 \\
\hline 2 & 1 & 2 & 5 & White-browed Scrubwren & 5 \\
\hline 2 & 1 & 1 & 5 & Crested Pigeon & $\mathrm{NC}$ \\
\hline 2 & 3 & 1 & 5 & Little Corella & $\mathrm{NC}$ \\
\hline 3 & 4 & 3 & 1 & Jacky Winter & 2 \\
\hline 3 & 4 & 2 & 3 & Scarlet Robin & 3 \\
\hline 3 & 4 & 8 & 1 & White-browed Woodswallow & $\mathrm{NC}$ \\
\hline 4 & 1 & 1 & 5 & Magpie-Lark & 4 \\
\hline 4 & 1 & 2 & 5 & Yellow-rumped Thornbill & 4 \\
\hline 4 & 1 & 1 & 5 & Rufous Songlark & 5 \\
\hline 4 & 1 & 4 & 2 & Silvereye & 5 \\
\hline 4 & 2 & 3 & 5 & Grey Currawong & 6 \\
\hline 4 & 1 & 1 & 2 & Brown-headed Honeyeater & 8 \\
\hline 4 & 1 & 5 & 2 & Red Wattlebird & 9 \\
\hline 4 & 1 & 3 & 2 & Common Bronzewing & 10 \\
\hline 4 & 1 & 1 & 5 & Galah & 10 \\
\hline 5 & 1 & 5 & 2 & Crested Shrike-tit & 6 \\
\hline 5 & 1 & 6 & 2 & Spotted Pardalote & 8 \\
\hline 5 & 1 & 6 & 2 & Striated Pardalote & 8 \\
\hline 6 & 8 & 3 & 2 & Golden Whistler & 7 \\
\hline 6 & 8 & 4 & 2 & Rufous Whistler & 7 \\
\hline 6 & 8 & 5 & 2 & White-eared Honeyeater & 7 \\
\hline 6 & 10 & 5 & 2 & White-plumed Honeyeater & 8 \\
\hline 6 & 10 & 5 & 2 & Little Wattlebird & 9 \\
\hline 6 & 10 & 4 & 2 & New Holland Honeyeater & 9 \\
\hline 7 & 8 & 2 & 5 & White-winged Triller & 7 \\
\hline 8 & 4 & 5 & 5 & Restless Flycatcher & 2 \\
\hline 8 & 4 & 2 & 5 & Willie Wagtail & 2 \\
\hline 8 & 4 & 2 & 5 & Red-capped Robin & 3 \\
\hline 9 & 8 & 4 & 2 & Western Gerygone & $\mathrm{NC}$ \\
\hline
\end{tabular}

${ }^{\mathrm{a}}$ Sweeper -1 ; hawker -2 ; pouncer -3 ; ground carnivore -4 ; bush carnivore -5 ; bark prober -6 ; wood searcher -7 ; foliage searcher -8 ; nectarivore -9 ; granivore -10 ; not classified - NC. ${ }^{b}$ Bird habitat functional group. ${ }^{\mathrm{c}} \mathrm{Glean} / \mathrm{peck} /$ pull - 1; probe $-2 ;$ scratch/chisel/dig/hammer/drill $-3 ;$ sally/screen -4 ; attack in or near the water $-5 ; 1+2-6 ; 1+$ $3-7 ; 1+4-8 ; 2+3-9 ; 1+2+4-10$. ${ }^{\mathrm{d}} 0$ meter in foraging height $(\mathrm{FG})-1 ;(0<\mathrm{FG}<1)-2 ;(1 \leq \mathrm{FG}<2)-3$; $(2 \leq \mathrm{FG}<4)-4 ; \quad(4 \leq \mathrm{FG}<8)-5 ; \quad(8 \leq \mathrm{FG}<12)-6 ; \quad(12 \leq \mathrm{FG}<16)-7 ; \quad(16 \leq \mathrm{FG}<20)-8 ; \quad(20 \leq \mathrm{FG}<24)-9 ;$ $(\mathrm{FG}>24)-10$. ${ }^{\mathrm{e}} \mathrm{Air}-1$; canopy/crown -2 ; perch -3 ; bark/stem -4 ; ground -5 ; water -6 . ${ }^{\mathrm{c}-\mathrm{e}}$ Partial components of multiple evaluation criteria of BHFGC to classify bird species (in shade).

otherwise not separated from each other by pure structural attributes alone. Therefore, they were considered as VHR variables in order to develop a more powerful classification scheme in this study.

To comprehend the BHFGC developed here, we compared our system with one based on well-known guilds, foraging guilds, which has been used for studying birds in southeastern Australia ${ }^{34}$. In the study by Mac Nally ${ }^{34}, 100$ bird species were classified into 10 different foraging guilds based on an analysis of foraging information, although some species could not be reliably assigned due to insufficient information with respect to low density and seasonal occurrence. Table 4 provides a list of 35 bird species that are common to the study of Mac Nally ${ }^{34}$ and the present study.

Compared with Mac Nally's ${ }^{34}$ perspective on foraging guild, the present study differs in certain important respects (Table 4). First, there is no direct correspondence between the foraging guilds and our BHFGs; for example, 'foraging guild 2' includes three of our BHFGs (BHFG 1, 3 and 8) and 'foraging guild 7' is related to BHFG 1, 6 and 7. Secondly, the results presented in Table 4 indicate a strong relationship between two different systems, namely foraging guild and attack method, 
the latter being one of the elements of BHFG, although it is not derived from the same perspective. For example, 'hawker', which corresponds to foraging guild 2, is comparable to 'sally' or 'screen' of attack method from BHFG 1, 3, and 8, which is linked to foraging guild 2, whereas 'ground carnivore' from foraging guild 3 is related to 'glean', 'peck' and/or 'pull' from BHFG 2 and 4 (Table 4).

Such comparisons serve to illustrate that these classification systems are independent of each other, as a single foraging guild can correspond to multiple BHFGs, and vice versa. However, using slightly different definitions of foraging guild or attack method (Table 4) could complicate outcomes. For example, sally and/or screen of attack methods in the BHFGC scheme are fully related to foraging guild 2 (hawkers) and foraging guild 3 (pouncers), and partially related to foraging guild 7 (wood searchers). In addition, because the BHFGC scheme includes a method for measuring the relative distance between habitat preferences for bird species, the composition of the BHFGs can vary according to the applied classifiers and input data regarding bird habitats. These issues in turn can be influenced by the quantity and quality of information and data, and also depend on the subjective decision-making of stakeholders. In this sense, the results here are considered to be a good example of a neutral guideline.

The most important aspect of the present study is our development of an approach for converting bird speciescentric information into vegetation structure-based numerical data. We propose that this approach is a more effective tool for anticipating the distribution of bird habitats, particularly in advance of conducting a largescale field campaign or project, compared to the tradition of relying solely on avian ecology information. Additionally, because the VHR variables were developed by focusing on vegetation structural features, they can readily be linked to remotely sensed data which are useful for surveying extensive study sites. Accordingly, using VHR variables implies that this BHFGC scheme, when used in conjunction with geographical information system and remote sensing techniques, can be expanded to modelling and predicting the spatial distribution of target species on a landscape scale for conservation purposes.

1. Mac Arthur, R. H. and Mac Arthur, J. W., On bird species diversity. Ecology, 1961, 42, 594-598.

2. Gilmore, A. M., The influence of vegetation structure on the density of insectivorous birds. In Birds of Eucalypt Forests and Woodlands: Ecology, Conservation, Management (eds Keast, A. et al.), Surrey Beatty \& Sons Pty Limited, Chipping Norton, NSW, Australia, 1985, pp. 21-31.

3. Hinsley, S. A., Hill, R. A., Fuller, R. J., Bellamy, P. E. and Rothery, P., Bird species distributions across woodland canopy structure gradients. Community Ecol., 2009, 10, 99-110.
4. Marchant, S. and Higgins, P. J., Handbook of Australian, New Zealand \& Antarctic Birds, Oxford University Press, Melbourne, Australia, 1st edn, 1990.

5. Rodewald, P. G. and Smith, K. G., Short-term effects of understory and overstory management on breeding birds in Arkansas oak-hickory forests. J. Wildl. Manage., 1998, 62, 1411-1417.

6. Clawges, R., Vierling, K., Vierling, L. and Rowell, E., The use of airborne lidar to assess avian species diversity, density, and occurrence in a pine/aspen forest. Remote Sensing Environ., 2008, 112, 2064-2073.

7. James, F. C., Ordinations of habitat relationships among breeding birds. Wilson Bull., 1971, 83, 215-236.

8. Donald, P. F., Fuller, R. J., Evans, A. D. and Gough, S. J., Effects of forest management and grazing on breeding bird communities in plantations of broadleaved and coniferous trees in western England. Biol. Convserv., 1998, 85, 183-197.

9. Braithwaite, L. W., Austin, M. P., Clayton, M., Turner, J. and Nicholls, A. O., On predicting the presence of birds in Eucalyptus forest types. Biol. Conserv., 1989, 50, 33-50.

10. Hagan, J. M. and Meehan, A. L., The effectiveness of stand-level and landscape-level variables for explaining bird occurrence in an industrial forest. For. Sci., 2002, 48, 231-242.

11. Swift, B. L., Larson, J. S. and DeGraaf, R. M., Relationship of breeding bird density and diversity to habitat variables in forested wetlands. Wilson Bull., 1984, 96, 48-59.

12. Arnold, G. W., The effects of habitat structure and floristics on the densities of bird species in Wandoo woodland. Aust. Wildl. Res., 1988, 15, 499-510.

13. Chettri, N., Deb, D. C., Sharma, E. and Jackson, D., The relationship between bird communities and habitat: a study along a trekking corridor in the Sikkim Himalaya. Mt. Res. Dev., 2005, 25, 235-243.

14. Watson, A., Judd, S., Watson, J., Lam, A. and Mackenzie, D., The Extraordinary Nature of the Great Western Woodlands, The Wilderness Society WA, Perth, Western Australia, 2008.

15. AUSLIG, Vegetation: Atlas of Australian Resources, The Australian Government Publishing Service, Canberra, ACT, Australia, 1990.

16. ABARES, Australian forest profiles, Department of Agriculture and Water Resources, Australian Government, Canberra, ACT; http://www.agriculture.gov.au/abares/forestsaustralia (accessed on 22 March 2016).

17. Pate, J. S. and Beard, J. S., Kwongan-Plant Life of the Sandplain, University of Western Australia Press, Perth, Western Australia, 1984, 1st edn.

18. Newby, K. R., The Biological Survey of the Eastern Goldfields of Western Australia: Records of the Western Australian Museum Part 1 and 2, Western Australian Museum and Western Australia Biological Surveys Committee, Perth, Western Australia, 1984.

19. Newby, K. R., The Biological Survey of the Eastern Goldfields of Western Australia: Records of the Western Australian Museum Part 3, Western Australian Museum and Western Australia Biological Surveys Committee, Perth, Western Australia, Australia, 1985.

20. Newby, K. R., The Biological Survey of the Eastern Goldfields of Western Australia: Records of the Western Australian Museum Part 4, Western Australian Museum and Western Australia Biological Surveys Committee, Perth, Western Australia, 1988.

21. Newby, K. R., The Biological Survey of the Eastern Goldfields of Western Australia: Records of the Western Australian Museum Part 8, Western Australian Museum and Western Australia Biological Surveys Committee, Perth, Western Australia, 1992.

22. Newby, K. R., The Biological Survey of the Eastern Goldfields of Western Australia: Records of the Western Australian Museum Part 9, Western Australian Museum and Western Australia Biological Surveys Committee, Perth, Western Australia, 1993. 
23. Newby, K. R., The Biological Survey of the Eastern Goldfields of Western Australia: Records of the Western Australian Museum Part 11 and 12, Western Australian Museum and Western Australia Biological Surveys Committee, Perth, Western Australia, 1995.

24. Beard, J. S., The natural regions of the deserts of Western Australia. J. Ecol., 1969, 57, 677-711.

25. Lee, P. S., Mackey, B. G. and Berry, S. L., Modelling vegetation structure-based bird habitat resources in Australian temperate woodlands, using multi-sensors. Eur. J. Remote Sensing, 2013, 46, 641-674.

26. Grubb Jr, T. C., Weather-dependent foraging behavior of some birds wintering in a deciduous woodland. Condor, 1975, 77, 175182.

27. Recher, H. F., Holmes, R. T., Schulz, M., Shields, J. and Kavanagh, R., Foraging patterns of breeding birds in eucalypt forest and woodland of southeastern Australia. Aust. J. Ecol., 1985, 10, 399-419.

28. Remsen, J. J. V. and Robinson, S. K., A classification scheme for foraging behavior of birds in terrestrial habitats. Stud. J. Avian Biol., 1990, 13, 144-160.

29. Kominami, Y., Sato, T., Takeshita, K., Manabe, T., Endo, A. and Noma, N., Classification of bird-dispersed plants by fruiting phenology, fruit size, and growth form in a primary lucidophyllous forest: an analysis, with implications for the conservation of fruit-bird interactions. Ornithol. Sci., 2003, 2, 3-23.

30. Elliott, C. P., Lindenmayer, D. B., Cunningham, S. A. and Young, A. G., Landscape context affects honeyeater communities and their foraging behaviour in Australia: implications for plant pollination. Landsc. Ecol., 2012, 27, 393-404.

31. Wells, K. et al., Trait-dependent occupancy dynamics of birds in temperate forest landscapes: fine-scale observations in a hierarchical multi-species framework. Anim. Conserv., 2012, 15, 1-12.

32. Wilson, M. F., Avian community organization and habitat structure. Ecology, 1974, 55, 1017-1029.

33. Antos, M. J. and Bennett, A. F., How important are different types of temperate woodlands for ground-foraging birds? Wildl. Res., 2005, 32, 557-572.

34. Mac Nally, R., Habitat-specific guild structure of forest birds in south-eastern Australia: a regional scale perspective. J. Anim. Ecol., 1994, 63, 988-1001.

ACKNOWLEDGEMENT. This work was supported by a research fund from Hanyang University (HY-2016), Seoul.

Received 22 October 2017; revised accepted 12 September 2018 